\section{Detection of Adulteration by Wedelia calendulacea in Eclipta alba through ISSR and RAPD Markers}

\author{
Santhosh Kumar Pendkar ${ }^{1 *}$, Satisha Hegde ${ }^{2 *}$, Shraddha \\ Umesh Nayak ${ }^{1}$, Harsha Hegde ${ }^{2}$, Sanjiva D. Kholkute ${ }^{2}$, Subarna \\ Roy $^{2}$ \\ ${ }^{1}$ Department of Dravyaguna, KLEU's Shri BMK Ayurveda Mahavidya- \\ laya, Belagavi, Karnataka, India \\ 2 Regional Medical Research Centre, Indian Council of Medical Re- \\ search, Department of Health Research (Govt of India), Belagavi, \\ Karnataka, India
}

\section{Abstract \\ $\nabla$}

In the crude herbal drug market, the highly medicinal Eclipta al$b a$, popularly known as "Bhringaraja", is often adulterated with Wedelia calendulacea. To evaluate the ability of simple genetic fingerprinting methods to differentiate between the two species, Inter-Simple Sequence Repeat and Random Amplified Polymorphic DNA assays were performed on 30 individuals of $E$. alba and 4 individuals of $W$. calendulacea. Samples of $W$. calendulacea were found to cluster in clades that distinctly separated from E. alba and at least one band was identified for each of the two species that can serve as a marker for identification. Despite wide variations and a limited number of samples, phylogenetic analysis helped in differentiating the original from the adulterant plant. The study underscores the importance of simple DNAbased fingerprinting as a cost-effective method for the detection of adulteration in plants, particularly with respect to $E$. alba.

Key words

Eclipta alba $\cdot$ Wedelia calendulacea $\cdot$ Asteraceae $\cdot$ phylogenetics - adulteration $\cdot$ molecular markers

\section{Abbreviations \\ $\nabla$ \\ ISSR: Inter-Simple Sequence Repeat \\ PCA: Principal Component Analysis \\ PCoA: Principal Coordinate Analysis \\ RAPD: Random Amplified Polymorphic DNA}

Supporting information available online at http://www.thieme-connect.de/products

Eclipta alba (L.) Hassk, commonly known as "Bhringaraja", is a medicinal herb belonging to the Asteraceae family that is traditionally used as a liver tonic and hair growth promoter in various traditional systems of medicine including Ayurveda. It is used in the treatment of spleen enlargements, uterine hemorrhages, skin diseases, and scorpion bites [1-4]. Other than the use of the whole plant juice as a powerful hepatoprotective and rejuvenative tonic, it is also used for the treatment of respiratory disorders, including coughs and asthma [5]. Wedelia calendulacea (L.) Less ("Pithabringi"), which belongs to the same family as E. alba,

\footnotetext{
* These authors contributed equally to this work.
}

has a similar common name, and has been known for similar therapeutic uses $[1,4]$. It is often used as a substitute for the latter. It is interesting to note that wedelectone, a coumestan, is one of the major polyphenolic active constituents found in both species and it has been reported for activities against breast and prostate carcinomas $[6,7]$.

Correct botanical identities of several crude drugs used in Ayurveda and in other traditional systems have not been properly established. These drugs have been categorized as "Sandigdha Dravya" or doubtful entities [8]. These are herbs with names that do not precisely indicate the exact botanical identity, but describe the therapeutic utility of the plant. The same is true with "Bhringaraja". Both E. alba and W. calendulacea are used under the name "Bhringaraja", often for treatment of the same ailment. However, it is reported that "Shweta Bhringaraja" - white-flowered herb (E. alba) - is superior in quality [9]. Reports of "E. alba" being adulterated with $W$. calendulacea are frequent $[2,10,11]$. Quality issues, including the genuineness of crude drugs are a major concern plaguing the herbal drug industry, particularly in India. The use of authentic medicinal plant species is a fundamental requirement in herbal medicine [12]. Adulteration, substitution, and mislabelling may cause potential harm to patients [13-17]. Along with safety and toxicity, there is a need to develop methods of profiling medicinal plants for the purpose of authentication. For genetic materials, which are more stable and uniform, DNA-based typing methods are increasingly being used for this purpose $[18,19]$. Methods like RAPD and ISSR fingerprinting are cost effective, relatively simple, and easy to perform. Although not always robust, they are techniques that yield results that can be interpreted to answer questions on genetic similarities, differences, and relatedness at reasonably lower costs and can be carried out at any laboratory that has a PCR facility. In the present study, such simple fingerprinting methods have been employed to identify and differentiate $E$. alba from its putative adulterant $W$. calendulacea.

Amplification of genomic DNA of 30 individuals of $E$. alba and 4 individuals of $W$. calendulacea using the two most reliable of seven ISSR primers tested yielded 23 scorable loci. Four out of the five RAPD primers tested showed clear band resolution and reproducibility. A total of 58 polymorphic loci were produced by the four RAPD primers. However, an assay with the ISSR primer UBC 880 showed the best discriminatory power and reproducibility amongst the primers employed in ISSR or RAPD assays during the present study (Fig. 1 S, Supporting Information). Jaccard's coefficient of similarity between all of the 34 individual plants ranged from 0.10 to 0.91 in the ISSR assay and from 0.04 to 0.97 in the RAPD assay. For cluster analysis, a similarity matrix was used to construct an unrooted phenetic dendrogram using the program PhyloWidget. It showed two main clades, one for E. Alba (EA) and the other for W. calendulacea (WC) in both the ISSR and RAPD assays ( Fig. 1). The WC group separated out from the EA group very early. Interestingly, in the ISSR assays, within the EA group, five minor clades were observed, in which EA 30 (clade IV) appeared as distinct ( $\bullet$ Fig. 1 b). Among the remaining minor clades, clade I consisted of 12 individuals (EA1, EA2, EA6, EA8, EA3, EA4, EA5, EA7, EA9, EA12, EA15, EA10), clade II consisted of 8 individuals (EA11, EA14, EA13, EA16, EA17, EA18, EA19, EA23), clade III of 5 individuals (EA21, EA25, EA27, EA28, EA29), and clade V of 4 individuals (EA20, EA26, EA24, EA22). Similarly, with the RAPD assays, EA and WC appeared as separate major clades ( Fig. 1a). Within the EA group, 9 minor clades appeared, in which EA1 (clade I) and EA10 (clade VIII) 


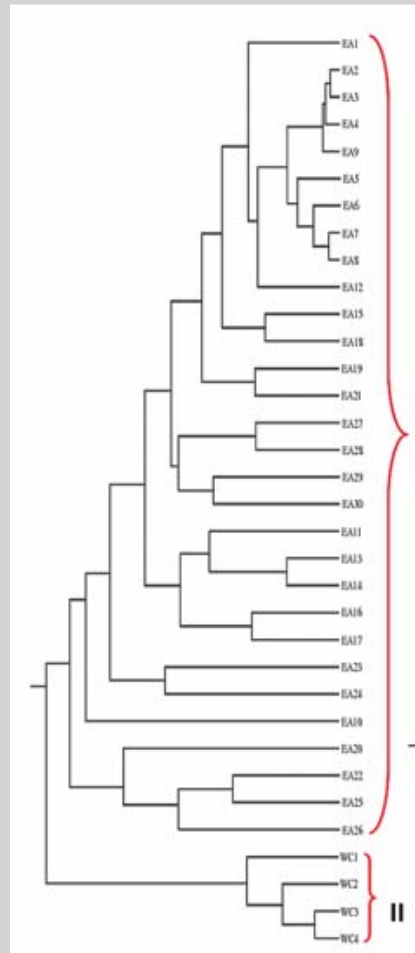

(a)

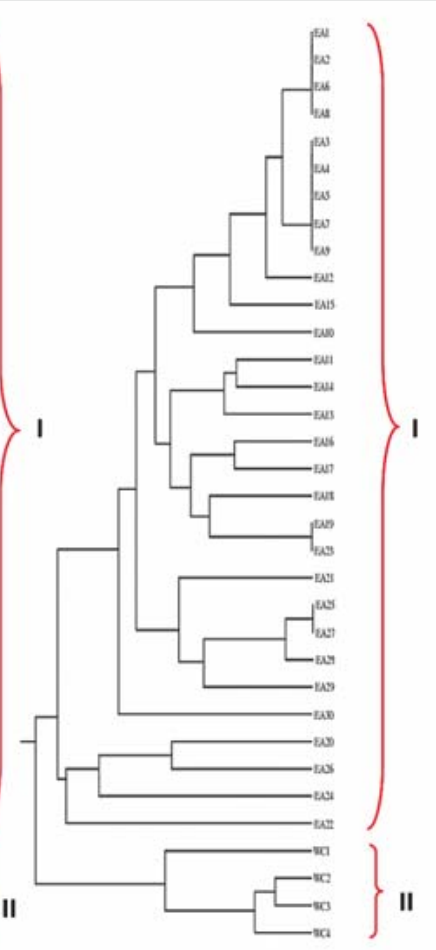

(b)
Fig. 1 a RAPD- and b ISSR-based UPGMA phenogram showing similarities amongst 30 individuals of $E$. alba (EA1 to EA30) and 4 individuals of W. calendulacea (WC1 to WC4).

were grouped as distinct clades. Among the minor clades, clade II consisted of 9 individuals (EA2, EA3, EA4, EA9, EA5, EA6, EA7, EA8, EA12), clade 3 consisted of 2 (EA15, EA18), clade IV of 2 (EA19, EA21), and clade VII of 2 (EA23, EA24) individuals, while clade $V$ had 4 individuals (EA27, EA28, EA29, EA30), clade VI had 5 (EA11, EA3, EA14, EA16, EA17), and clade XI had 4 individuals (EA20, EA22, EA25, EA26). Both unrooted phenograms showed genetic divergence within the EA, while EA differentiated from WC distinctly.

In general, ISSR showed $86.96 \%$ polymorphic loci and RAPD showed $91.38 \%$. Tangentially, the number of effective alleles $(\mathrm{Ne})$, Shannon's information index $(I)$, and diversity $(h)$ were also analyzed (see Supporting Information), whereby it was found that EA exhibited a wide genetic divergence even though this particular study was limited in the geographical range of the plants covered.

In PCoA, EA appeared separated from WC, although they were observed to be close to each other ( Fig. 2 a, b). PCA also revealed the genetic relatedness between EA and WC ( $\bullet$ Fig. 2 c, d, e, and f). Similar to PCoA, in PCoA also the WC and EA were found to be close to each other. This is perhaps due to the fact that both EA and WC belong to the same family and share some common characters. It may be noted that due to this closeness, there might be some similarity in their chemo profiles, which might in turn account for similar biological activity and similar medicinal use. However, in both PCoA and PCA analyses, individual samples showed clustering into two groups of distinct genetic pools of respective taxa ( $\odot$ Fig. 2) facilitating differential identification.
Adulteration and substitution of drugs may be intentional or unintentional. Misidentification of a particular herb results in substitution unknowingly, while intentional adulteration is done with less expensive herbs instead of the actual herb, which is generally more expensive [20]. Among the various available methods of quality control, pharmacognostic assays are timeconsuming and laborious and therefore are a deterrent for wide use. Development of phytochemical markers are dependent on various factors like environmental conditions, age of plant, soil condition, harvesting time, etc., which tend to fluctuate the chemical constituents and therefore lack uniformity, which is necessary to be used as a tool. Therefore, DNA-based technologies, which are more stable and reliable, have clear advantage over these traditional methods. Although DNA barcoding, extreme PCR, or high-resolution melting analysis provide more authentic and accurate results, cost-effective and reliable identification tools like ISSR and RAPD markers have been considered advantageous since they can be carried out in reasonably equipped laboratories [19,21-23]. In the present study, phylogenetic inference coupled with PCA and PCoA effectively resolved and clearly differentiated $W$. calendulacea from $E$. alba. Although limited in number and scope, the present study highlights the usefulness of simple DNA-based techniques in the differentiation of the important medicinal plants E. alba and W. calendulacea.

\section{Materials and Methods \\ $\nabla$}

Leaves from 30 individual plants of $E$. alba and 4 plants of $W$. calendulacea were collected from the Western Ghats region of Karnataka, India (latitudes $15^{\circ} 42^{\prime} \mathrm{N}$ to $16^{\circ} 7^{\prime} \mathrm{N}$, longitudes $74^{\circ} 3^{\prime} \mathrm{E}$ to $74^{\circ} 41^{\prime} \mathrm{E}$; Table $1 \mathrm{~S}$, Supporting Information). The plant samples were identified by a qualified taxonomist and voucher specimens for E. alba (voucher number: RMRC - 982) and W. calendulacea (voucher number: RMRC - 983) were deposited in the herbarium at the Regional Medical Research Centre, Belagavi, India. DNA from all leaf samples were extracted by a modified CTAB method. The stock DNA thus obtained was diluted to $30 \mathrm{ng} / \mu \mathrm{L}$ as a working dilution. ISSR and RAPD assays were performed at least twice with each primer to confirm the reproducibility of the bands. Only the consistent and reproducible bands were considered for scoring and subsequent analysis. Negative controls that consisted of reaction mixtures without a DNA template were used during both of the fingerprinting assays. For each genotype, the presence ( 1 ) or absence $(0)$ of bands were scored as a binary matrix. Phenetic dendrograms were generated and genetic variations exhibited were derived by PCA and PCoA by using a binary matrix (see Supporting Information).

\section{Supporting information}

Detailed information of genetic diversity and materials and methods are provided as Supporting Information.

\section{Acknowledgements \\ $\nabla$}

The authors are thankful to the Indian Council of Medical Research for supporting this study through the intramural funds of RMRC, Belagavi and KLE University's Shri BMK Ayurveda Mahavidyalaya, Belagavi, India. The informatics and technical help rendered by the Bio-Medical Informatics Centre of ICMR at RMRC Belagavi is also thankfully acknowledged. 


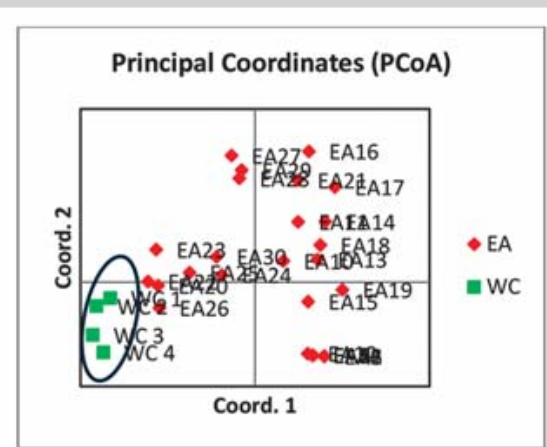

(a)

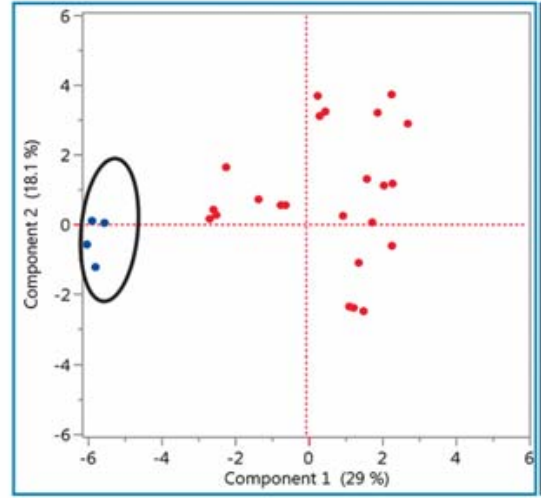

(c)

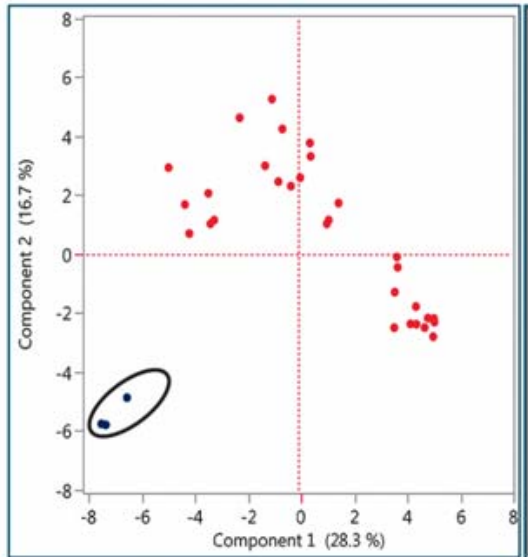

(e)

\section{Principal Coordinates (PCoA)}

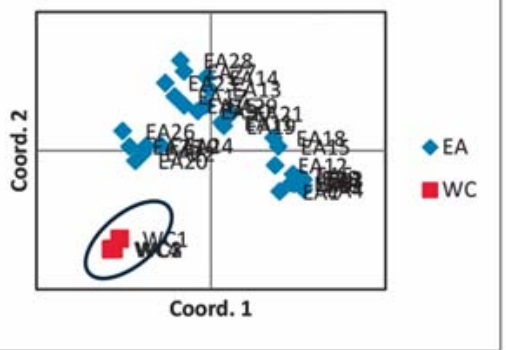

(b)

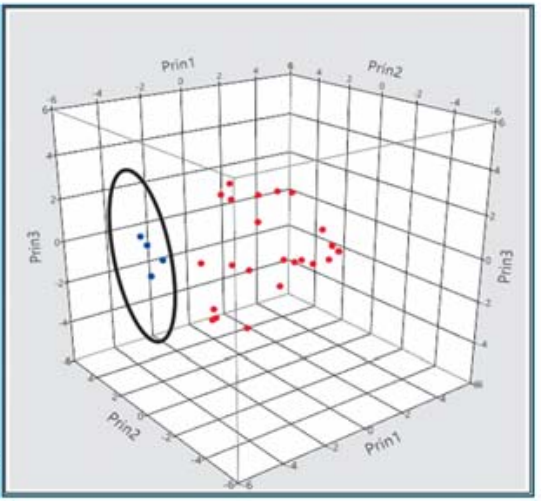

(d)

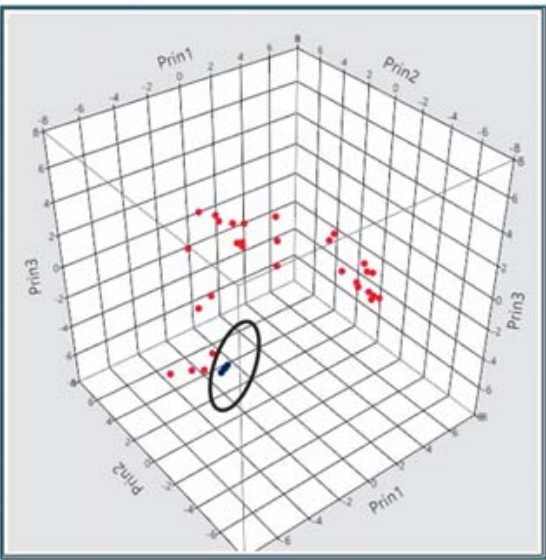

(f)
Fig. 2 a ISSR-based Principal Coordinate Analysis (PCoA), b RAPD-based Principal Coordinates Analysis (PCoA), c Score plot, and d 3D scatter plot of Principal Component Analysis (PCA) from ISSR markers. (e) Score plot and (f) 3D scatter plot of principal component analysis (PCA) from RAPD markers. In the diagrams, WC samples are circled.

\section{Conflict of Interest}

The authors declare no conflict of interest.

\section{References}

1 Nadkarni KM. Indian Materia Medica, Vol. 1. Bombay: Popular Prakashan; 1976: 469-470

2 Sarin YK. Illustrated Herbs of Ayurveda. New Delhi, India: Council of Scientific \& Industrial Research (CSIR) and Indian council of Medical Research (ICMR); 1996: 263

3 Pithayanukul P, Laovachirasuwan S, Bavovada R, Pakmanee N, Suttisri R. Anti-venom potential of butanolic extract of Eclipta prostrata against Malayan pit viper venom. J Ethnopharmacol 2004; 90: 347-352

4 Khare CP. Indian medicinal Plants: an illustrated Dictionary. New York: Springer; 2007: 230, 716

5 Chunekar KC. Bhavaprakasha Nighantu-Hindi Vyakhya. Varanasi, India: Chaukhambha Bharati Academy; 2004: 429
6 Wagner H, Fessler B. [In vitro 5-lipoxygenase inhibition by Eclipta alba extracts and the coumestan derivative wedelolactone]. Planta Med 1986; 5: 374-377

7 Nehybova T, Smarda J, Daniel L, Brezovsky J, Benes P. Wedelolactone induces growth of breast cancer cells by stimulation of estrogen receptor signalling. J Steroid Biochem Mol Biol 2015; 152: 76-83

8 Dixit VK. Controversial Ayurvedic herbs. J Adv Pharm Technol Res 2011; 2: 78-80

9 Pandit N. Raja Nighantu. Ed: Tripati I. Varanasi, India: Chaukhamba Khrishnadas Academy; 1983

10 Bapalal V. Some controversial drugs in Indian medicine. Varanasi, India: Chaukambha Orientalia; 1982: 155-156

11 Lucas SK. Dravyaguna Vijñāna, Vol 2. Varanasi, India: Chaukambha Vishwabharati; 2008: 234

12 Govindaraghavan S, Hennell JR, Sucher NJ. From classical taxonomy to genome and metabolome: towards comprehensive quality standards for medicinal herb raw materials and extracts. Fitoterapia 2010; 83: 979-988 
13 Newmaster SG, Grguric M, Shanmughanandhan D, Ramalingam S, Ragupathy S. DNA barcoding detects contamination and substitution in North American herbal products. BMC Med 2013; 11: 222

14 Seethapathy GS, Ganesh D, Santhosh Kumar JU, Senthilkumar U, Newmaster, SG, Ragupathy S, Uma Shaanker R, Ravikanth G. Assessing product adulteration in natural health products for laxative yielding plants, Cassia, Senna, and Chamaecrista, in Southern India using DNA barcoding. Int J Legal Med 2014; 129: 693-700

15 Xin T, Li X, Yao H, Lin Y, Ma X, Cheng R, Song J, Ni L, Fan C, Chen S. Survey of commercial Rhodiola products revealed species diversity and potential safety issues. Sci Rep 2015; 5: 8337

16 Williamson EM, Chan $K, X u Q$ Nachtergael A, Bunel V, Zhang L, Ouedraogo M, Nortier J, Qu F, Shaw D, Liu X, Stévigny C, Kahumba J, Pelkonen O, Duez P. Evaluating the safety of herbal medicines: Integrated toxicological approaches. Science 2015; 347: S47-S49

17 Quinto CA, Tinoco R, Hellberg RS. DNA barcoding reveals mislabeling of game meat species on the U.S. commercial market. Food Control 2016; 59: 386-392

18 Coutinho Moraes DF, Still DW, Lum MR, Hirsch AM. DNA-based authentication of botanicals and plant-derived dietary supplements: where have we been and where are we going? Planta Med 2015; 81: 687-695

19 Mishra P, Kumar A, Nagireddy A, Mani DN, Shukla AK, Tiwari R, Sundaresan $V$. DNA barcoding: an efficient tool to overcome authentication challenges in the herbal market. Plant Biotechnol J 2015; 14: 821

20 Kiran U, Khan S, Mirza KJ, Ram M, Abdin MZ. SCAR markers: a potential tool for authentication of herbal drugs. Fitoterapia 2010; 81: 969-976

21 Osathanunkul M, Madesis P, de Boer H. Bar-HRM for authentication of plant-based medicines: evaluation of three medicinal products derived from Acanthaceae species. PLoS One 2015; 10: e0128476
22 Farrar JS, Wittwer CT. Extreme PCR: efficient and specific DNA amplification in 15-60 seconds. Clin Chem 2014; 61: 145-153

23 Tamhankar S, Ghate V, Raut A, Rajput B. Molecular profiling of "Chirayat" complex using Inter Simple Sequence Repeat (ISSR) markers. Planta Med 2009; 75: 1266-1270

\section{received October 30, 2015}

revised April 29, 2016

accepted May 2, 2016

\section{Bibliography}

DOI http://dx.doi.org/10.1055/s-0042-108742

Planta Med Int Open 2016; 3: e43-e46

(c) Georg Thieme Verlag KG Stuttgart · New York .

ISSN 2509-6656

\section{Correspondence}

\section{Dr. Subarna Roy}

Regional Medical Research Centre Indian Council of Medical Research Department of Health Research (Govt of India) Nehru Nagar

Belagavi, Karnataka - 590010 India

Phone: + 91831247547778

Fax: + 918312475479

roys@icmr.org.in

\section{License terms \\ ()ㅜ (1) $\Theta \circledast$}

